\title{
Prevalence of antisocial personality disorder and other psychopathologies among drug addicts and nondependent psychiatric patients
}

\author{
Okechukwu J Oguizu' ${ }^{*}$, Ada D Oguizu ${ }^{2}$ and William N Ebiti ${ }^{3}$ \\ ${ }^{1}$ Clinical Psychology Department, Department of Clinical Services, Federal Neuropsychiatric Hospital, Barnawa, Kaduna, Nigeria \\ ${ }^{2}$ Department of Human Nutrition and Dietetics, Michael Okpara University of Agriculture, Umudike, Nigeria \\ ${ }^{3}$ Department of Clinical Services, Federal Neuropsychiatric Hospital, Barnawa, Kaduna, Nigeria
}

\begin{abstract}
Objectives: To find whether antisocial personality disorder (ASPD) and other psychopathologies play a role among drug addicts and non-drug addict psychiatric patients in the development/manifestation of substance dependence problems.

Method: The sample size comprised one hundred and twenty (120) patients. Sixty (60) patients from Drug Alcohol Treatment Education and Rehabilitation (DATER) unit of Federal Neuropsychiatric Hospital, Barnawa, Kaduna. While the remaining sixty (60) patients from male and female wards of the same hospital who are nondependent psychiatric patients. DSM-V diagnostic criteria were applied to diagnose antisocial personality disorder and psychopathology as associated with substance dependence by the Psychiatrists while Clinical Psychologists administered Minnesota Multiphasic Personality Inventory (MMPI-2) to further ascertain the presence of psychopathology and personality.

Results: The results of this study showed a statistical significance difference between antisocial personality disorder patients and non-antisocial personality disorder patients at $\mathrm{t}(118)=6.45 \mathrm{p}<.01$, a statistical significance difference between patients with psychopathology namely; mania, paranoid, schizophrenia, psychasthenia and hypochondriasis and patients without psychopathology, all at $\mathrm{p}<.01$. Also, there exist a statistical significance difference in relationship between antisocial personality disorder and other psychopathologies at $\mathrm{p}<.01$.
\end{abstract}

Conclusion: The overall findings in this study lends support to the hypothesis, that the prevalence of antisocial personality disorder (ASPD) and other psychopathologies are contributing factors to the development/manifestation of substance dependence problems among drug addicts.

\section{Introduction}

A look at the number of patients on admission in psychiatric hospitals with respect to predisposition/development of mental disorder are patients with substance dependent problem. Literature has revealed that an association exist between drug addiction and psychopathology. Drug addicts have shown to have high rate of psychopathology example, depression etc. [1-4]. They indicated that development/manifestation of psychopathology and substance dependence in drug dependent persons are on alarming rate and have led to more individuals with substance dependence related problems. A co-morbid personality study carried out by also indicated that substance related problems/disorders and personality disorders are impossible to untie, each affecting the other [5].

Psychopathology is generally described as the behaviors or experiences which are indicative of mental illness. They include any behavior or experience that causes distress, impairment or disability especially one that manifest as a functional breakdown due to cognitive or neurocognitive problem in the brain. Examples of psychopathology/ mental disorders classified within the Diagnostic Statistical Manual Fifth Edition, (DSM-V) of American Psychiatric Association and International Statistical Classification of Diseases and Related Health Problems (ICD-10) include; schizophrenia, major depression, bipolar disorders, antisocial personality disorder, borderline personality disorder, phobias etc. [6,7].
Psychopathology in relation to substance dependence has been given to the issue of comorbid psychiatric and substance use disorders (SUD) since 1980's. This otherwise known as dual disorders, in clinical studies and community, has shown its prevalence $[3,8]$. In addition, indicated that there is high prevalence rate of substance dependence with psychopathology [2].

Personality disorder especially antisocial personality disorder (ASPD) according to DSM-V puts it as:

"A. A pervasive pattern of disregard for and violation of the right of others, occurring since the age of 15 years, as indicated by three (or more) of the Following:

1. Failure to conform to social norms with respect to lawful behaviors, as indicated by repeatedly performing acts that are grounds for arrest

${ }^{\star}$ Correspondence to: Okechukwu J Oguizu, Clinical Psychology Department, Department of Clinical Services, Federal Neuropsychiatric Hospital, Barnawa, Kaduna, E-mail: okechukwuoguizu@gmail.com

Key words: antisocial personality disorder, drug addiction/dependence, drug addicts, psychopathology

Received: June 05, 2018; Accepted: June 13, 2018; Published: June 16, 2018 
2. Deceitfulness, as indicated by repeated lying, use of aliases, or conning others for personal profit or pleasure

3. Impulsivity or failure to plan ahead

4. Irritability and aggressiveness, as indicated by repeated physical fight or assaults

5. Reckless disregard for safety of self or others

6. Consistent irresponsibility, as indicated by repeated failure to sustain consistent work behavior or honor financial obligations

7. Lack of remorse, as indicated by being indifferent to or rationalizing having hurt, mistreated/or stolen from another

B. The individual is at least age 15 years

\section{There is evidence of conduct disorder with onset before 15 years}

D. The occurrence of antisocial behavior is not exclusively during the worse of Schizophrenia or bipolar disorder". (DSM-V, 2013, p.659)

Indicated the prevalence of antisocial personality disorder among drug addicts $[2,9,10]$. They describe antisocial personality disorder as a type of personality disorder usually develop during childhood or early adolescence and persist into adulthood. They went further to say that is characterized by antisocial, irresponsible behavior and lack of remorse for misdeeds. According to them, antisocial personality disorder is considered imperative to contributing and/or predisposing factor in substance and psychopathology. Grant et al.'s study in 2006, concurred to this [11].

There are speculations that there is a relationship or association between antisocial personality disorder and psychopathology especially in substance dependent individuals and nondependent psychiatric patients. The rate of mental illness especially substance related problems is on increase and it has also observed that drug addicts have shown to have high rate of antisocial personality disorder, depression and other psychopathologies $[1,3,12]$.

In addition, mental health professionals, for example, Clinical Psychologists, Psychiatrists, Psychiatric Nurses etc., observe many cases of substance related mental illness in most psychiatric hospitals or drug rehabilitation centers. However, there is almost no study confirming the situation especially in the northern Nigeria. The dearth of available studies on antisocial personality disorder and psychopathology on substance dependent problems in general and specific using Nigeria sample prompted the researcher to undertake this study. The present study contributes to the literature on personality, psychopathology and substance dependence by using a Nigeria sample drawn from the psychiatric hospital setting.

This study therefore, focused on prevalence of antisocial personality disorder and psychopathology among drug addicts both past inpatients and outpatients of Drug Alcohol Treatment Education and Rehabilitation (DATER) unit and nondependent psychiatric patients of Federal Neuropsychiatric Hospital Barnawa, Kaduna. It was hypothesized that:

1) Antisocial personality disorder participants will obtain higher substance dependence scores than non-antisocial personality disorder participants among drug addicts and nondependent psychiatric patients.

2) Psychopathology participants will obtain higher substance dependence scores than participants without psychopathology among drug addicts and nondependent psychiatric patients.
3) There will be relationship effect between antisocial personality disorder and other psychopathologies in the development of substance dependence problems among drug addicts.

\section{Method}

\section{Participants}

The sample consist of hundred and twenty (120) participants (87 males and 33 females, aged 18 years and above). Of this 120 participants, fifty (50) males and females inpatients (Drug Addicts) were admitted into Federal Neuropsychiatric hospital, (FNPN), Barnawa, Kaduna. Ten (10) patients (drug addicts) were recruited as an outpatients. Both fifty (50) inpatients from the ward and ten (10) out patients were admitted into Drug Alcohol Treatment Education and Rehabilitation (DATER) unit of FNPH, Kaduna, for rehabilitation eventually were recruited for the study. These participants/patients are those rehabilitated in 2013-2014 in DATER unit. Another sixty participants (nondrug addict psychiatric patients) were also recruited. The consent of all the participants were sort, obtained and assured of absolute confidentiality. The Health Research Ethical Committee of Federal Neuropsychiatric Hospital, Barnawa, Kaduna, where the study was conducted approved the study. For the purposes of the present study, classification of the 120 patients sample into antisocial personality disorder (that is, drug addicts and nondependent psychiatric patients) and psychopathology (that is, drug addicts and nondependent psychiatric patients) were required.

\section{Stimulus material/instruments}

Apart from the diagnosis made by the Consultant Psychiatrist, Clinical Psychologist, made use of the psychological assessment instrument namely Minnesota Multiphasic Personality Inventory (MMPI-2) to further ascertain presence of psychopathology and antisocial personality disorder. MMPI-2 is an objective assessment instrument globally use in assessing the presence of psychopathology and personality. It contains about 567 items. The reliability and validity coefficients are within the range of .82 to .90 .

\section{Procedure}

The study was made possible by the members of the Health Research Ethical Committee of Federal Neuropsychiatric Hospital (FNHP), Barnawa, Kaduna. They approved the research and permitted that the study be conducted in the DATER unit and in the male and female wards of the hospital. The clinical interview and diagnosis was made by the Consultant Psychiatrist. However, Clinical Psychologist further conducted clinical interview and assessment with the use of psychological assessment instrument called MMPI-2 to further ascertain diagnosis, presence of psychopathology and personality, before they were finally recruited into the study. Before this, the oral consent of the drug addicts and nondependent psychiatric patients were sort and obtained. Before they were recruited into DATER for rehabilitation, Clinical Psychologist, conducted motivational interview for the patients both inpatients and outpatients. DATER resident doctor also reviewed them on motivational interview to ascertain their level of motivation for DATER. After the above have been conducted by the Clinical Psychologist and resident doctor in DATER, the participants were further taken in for intake interview. This time being assessed by DATER therapeutic team comprised of Consultant Psychiatrist, Clinical Psychologists, Psychiatrist Nurses, Medical Social Workers and Occupational Therapist, to finally ascertain their motivational level. These participants were found motivated by the therapeutic team and on that bases were recruited for the study. 


\section{Design/statistics}

The study is a cross sectional design. It consist of two independent variables (I.Vs); antisocial personality disorder (with antisocial personality disorder and those without antisocial personality disorder) and psychopathology (with and without psychopathology). Drug addicts and nondependent psychiatric patients serves as the dependent variables (D. Vs). A t test analysis with statistical package for social sciences (SPSS), version 22 (latest version) was applied to analysis the data for the first and second hypotheses while Pearson correlational analysis was used for third hypothesis with equal sample size.

\section{Results}

The results of the study include the following:

Table 1 showed the background information of respondents. About $72.5 \%$ of the respondents were male while $27.5 \%$ were females. For ASPD score $63.5 \%$ had ASPD, while $27.5 \%$ participants had no ASPD. About $51.7 \%$ had schizophrenia, while $48.3 \%$ were normal. For Mania score; $34.2 \%$ of participants had mania, while $65.8 \%$ were normal. About $30 \%$ of the subjects had Depression while $70 \%$ were normal. Close to a quarter of the respondents (38.3\%) were paranoid while $61.7 \%$ were normal. Hypochondriasis was present in $17.5 \%$ of the participants while $82.5 \%$ were normal. For Psychasthenia score; $10.8 \%$ of participants had psychasthenia while $89.2 \%$ were normal. (Table 2)

Table 1. Background information of respondents

\begin{tabular}{|c|c|c|}
\hline Variable & Frequency & Percentage \\
\hline \multicolumn{3}{|l|}{ Sex } \\
\hline Male & 87 & 72.5 \\
\hline Female & 33 & 27.5 \\
\hline Total & 120 & 100 \\
\hline \multicolumn{3}{|l|}{ ASPD Score } \\
\hline ASPD Disorder & 76 & 63.5 \\
\hline Non ASPD Disorder & 33 & 27.5 \\
\hline Total & 120 & 100 \\
\hline \multicolumn{3}{|l|}{ Schizophrenia Score } \\
\hline Schizophrenia & 62 & 51.7 \\
\hline Normal & 58 & 48.3 \\
\hline Total & 120 & 100 \\
\hline \multicolumn{3}{|l|}{ Mania Score } \\
\hline Mania & 41 & 34.2 \\
\hline Normal & 79 & 65.8 \\
\hline Total & 120 & 100 \\
\hline \multicolumn{3}{|l|}{ Depression Score } \\
\hline Depression & 36 & 30 \\
\hline Normal & 84 & 70 \\
\hline Total & 120 & 100 \\
\hline \multicolumn{3}{|l|}{ Paranoid Score } \\
\hline Paranoid & 46 & 38.3 \\
\hline Normal & 74 & 61.7 \\
\hline Total & 120 & 100 \\
\hline \multicolumn{3}{|l|}{ Hypochondriasis Score } \\
\hline Hypochondriasis & 21 & 17.5 \\
\hline Normal & 99 & 82.5 \\
\hline Total & 120 & 100 \\
\hline \multicolumn{3}{|l|}{ Psychasthenia Score } \\
\hline Psychasthenia & 13 & 10.8 \\
\hline Normal & 107 & 89.2 \\
\hline Total & 120 & 100 \\
\hline
\end{tabular}

Note: $A S P D=$ Antisocial personality disorder
Table 2: Table of mean scores and standard deviation for antisocial personality disorder on drug addict and non-dependent psychiatric patients

\begin{tabular}{|c|c|c|c|c|c|}
\hline \multicolumn{5}{|c|}{ Group Statistics } \\
\hline & Category of patients & N & Mean & $\begin{array}{c}\text { STD. } \\
\text { Deviation }\end{array}$ & $\begin{array}{c}\text { STD. } \\
\text { error } \\
\text { Mean }\end{array}$ \\
\hline $\begin{array}{c}\text { Antisocial } \\
\text { pers. Dis. } \\
\text { Score }\end{array}$ & $\begin{array}{c}\text { Drug addict } \\
\text { Non-drug addict psychiatric } \\
\text { patient }\end{array}$ & 60 & 1.22 & .415 & .054 \\
\hline
\end{tabular}

The scores obtained from antisocial personality disorder among drug addicts and non-drug addict psychiatric patients served as the dependent measure for the study. The mean scores and standard deviation of the groups compared showed that antisocial personality disorder among drug addicts had different score than non-dependent psychiatric patients (Table 3).

The mean scores and standard deviation of the groups compared showed that psychopathology example, schizophrenia, mania, paranoid, depression, hypochondriasis and psychasthenia among drug addicts (dependents) had different scores than non-drug addict psychiatric patients (Table 4).

It could be seen from the summary table 4 that $\mathrm{t}$ test analysis performed on the data showed that there was a significant main effect of antisocial personality, $t(118)=-3.56 \mathrm{p}<0.01$. That is to say that, the presence of antisocial personality disorder among drug addicts differed significantly with non-drug addict psychiatric patients. This finding support the first hypothesis, which predicted a statistical significant difference between participants with antisocial personality disorder and non-antisocial personality disorder in the development of substance dependent problems (Table 5).

It could be seen from the summary table that $t$ test analysis performed on the data showed that there was a significant main effect of psychopathology, example, Mania, t (118) = -4.80, $\mathrm{p}<.001$, Paranoid, $\mathrm{t}(118)=-4.42, \mathrm{p}<.001$, Schizophrenia, $\mathrm{t}(118)=-6.28, \mathrm{p}<$ .001 , Hypochondriasis, $\mathrm{t}(118)=-4.37$, and Psychasthenia, $\mathrm{t}(118)=$ $-2.70, \mathrm{p}<.001$, except Depression that wasn't significant. This is to say that, the presence of psychopathology namely mania, paranoid, schizophrenia, hypochondriasis and psychasthenia among drug addicts differed significantly with non-drug addict psychiatric patients. This finding support the second hypothesis which predicted that a statistical significant difference exist between participants with psychopathology and those without psychopathology in the development of substance dependent problems (Table 6).

It could also be seen that from the summary table above, that the Pearson correlation analysis performed on the data indicated that relationship effect were significant, example, ASPD with schizophrenia were significant at $\mathrm{r}=.198, \mathrm{p}<.01$, ASPD with mania were highly significant at $\mathrm{r}=.282, \mathrm{p}<.01$, ASPD with paranoid schizophrenia were highly significant at $\mathrm{r}=.282, \mathrm{p}<.01$, ASPD with hypochondriasis were highly significant at $\mathrm{r}=.314, \mathrm{p}<.01$, and ASPD with psychasthenia were highly significant at $\mathrm{r}=.283, \mathrm{p}<.01$, expect depression that was not significant.

The above indicate that as ASPD is increasing, schizophrenia also increases. This also applies to ASPD with mania, paranoid schizophrenia, hypochondriasis and psychasthenia. That is to say that, the presence of antisocial personality disorder and psychopathology namely schizophrenia, mania, paranoid schizophrenia, psychasthenia and hypochondriasis among drug addicts are responsible or accounts 
Table 3. Table of mean scores and standard deviation for psychopathology on drug addicts and non-drug addict psychiatric patients

\begin{tabular}{|c|c|c|c|c|c|}
\hline \multicolumn{6}{|c|}{ Group statistics } \\
\hline & Catergory of patients & $\mathbf{N}$ & Mean & STD. Deviation & STD. Error mean \\
\hline \multirow{2}{*}{ Psychopatholgy } & Drug Addict & 60 & 3.20 & 2.496 & .322 \\
\hline & Non-Drug Addict Psychiatric Patient & 60 & 2.12 & 1.595 & .206 \\
\hline \multirow{2}{*}{ Mania score } & Drug Addict & 60 & 1.47 & .503 & .065 \\
\hline & Non-Drug Addict Psychiatric Patient & 60 & 1.85 & .360 & .046 \\
\hline \multirow{2}{*}{ Paranoid score } & Drug Addict & 60 & 1.43 & .500 & .065 \\
\hline & Non-Drug Addict Psychiatric Patient & 60 & 1.80 & .403 & .052 \\
\hline \multirow{2}{*}{ Schizophrenia score } & Drug Addict & 60 & 1.23 & .427 & .055 \\
\hline & Non-Drug Addict Psychiatric Patient & 60 & 1.73 & .446 & .058 \\
\hline \multirow{2}{*}{ Depression score } & Drug Addict & 60 & 1.68 & .469 & .061 \\
\hline & Non-Drug Addict Psychiatric Patient & 60 & 1.72 & .454 & .059 \\
\hline \multirow{2}{*}{ Hypochondriasis score } & Drug Addict & 60 & 1.68 & .469 & .061 \\
\hline & Non-Drug Addict Psychiatric Patient & 60 & 1.97 & .181 & .023 \\
\hline \multirow{2}{*}{ Psych asthenia score } & Drug Addict & 60 & 1.82 & .390 & .050 \\
\hline & Non-Drug Addict Psychiatric Patient & 60 & 1.97 & .181 & .023 \\
\hline
\end{tabular}

Table 4. A summary table of $t$ test analysis on antisocial personality disorder with equal sample size showing difference among drug addicts and non-drug psychiatric patients

\begin{tabular}{|c|c|c|c|c|c|c|c|c|}
\hline \multicolumn{9}{|c|}{ Independent samples test } \\
\hline & & \multicolumn{2}{|c|}{$\begin{array}{l}\text { Levene's test for equality of } \\
\text { variances }\end{array}$} & \multicolumn{5}{|c|}{ T-test for equality of means } \\
\hline & & $\mathbf{F}$ & SIG. & $\mathbf{T}$ & DF & $\begin{array}{c}\text { SIG. } \\
\text { (2-TAILED TEST) }\end{array}$ & MEAN DIFF. & $\begin{array}{l}\text { STD. ERROR } \\
\text { DIFF }\end{array}$ \\
\hline \multirow{2}{*}{ Aspd score } & Equal variances assumed & 27.574 & .000 & -3.558 & 118 & .001 & -3.000 & .084 \\
\hline & Equal variances not assumed & & & -3.558 & 113.858 & .001 & -3.000 & .084 \\
\hline
\end{tabular}

$\mathrm{P}<.01$

Note. ASPD $=$ Antisocial personality disorder

Table 5. A summary table of t test analysis on psychopathology with unequal sample size, example (mania, paranoid, schizophrenia, hypochondriasis and psychasthenia) showing differences among drug addicts and non-drug addicts psychiatric patients

\begin{tabular}{|c|c|c|c|c|c|c|c|c|c|c|}
\hline & & \multicolumn{2}{|c|}{$\begin{array}{c}\text { Levene's Test for } \\
\text { Equality of Variances }\end{array}$} & \multicolumn{7}{|c|}{ T-test for Equality of Means } \\
\hline & & \multirow[t]{2}{*}{$\mathbf{F}$} & \multirow[t]{2}{*}{ SIG } & \multirow[t]{2}{*}{$\mathbf{T}$} & \multirow[t]{2}{*}{ DF } & \multirow{2}{*}{$\begin{array}{c}\text { SIG. } \\
\text { (2-tailed) }\end{array}$} & \multirow{2}{*}{$\begin{array}{c}\text { Mean } \\
\text { Diff }\end{array}$} & \multirow{2}{*}{$\begin{array}{l}\text { STD ERROR } \\
\text { DIFF. }\end{array}$} & \multicolumn{2}{|c|}{$\begin{array}{l}\text { 95\% Confidence Interval of } \\
\text { the Difference }\end{array}$} \\
\hline & & & & & & & & & LOWER & UPPER \\
\hline \multirow{2}{*}{ Psychopathology } & Equal variances assumed & 12.037 & .001 & 2.833 & 118 & .005 & 1.083 & .382 & .326 & 1.841 \\
\hline & Equal variances not assumed & & & 2.833 & 100.313 & .006 & 1.083 & .382 & .325 & 1.842 \\
\hline \multirow{2}{*}{$\begin{array}{c}\text { Mania } \\
\text { Score }\end{array}$} & Equal variances assumed & 54.694 & .000 & -4.799 & 118 & .000 & -.383 & .080 & -.542 & -.225 \\
\hline & Equal variances not assumed & & & -4.799 & 106.883 & .000 & -.383 & .080 & -.542 & -.225 \\
\hline \multirow{2}{*}{$\begin{array}{l}\text { Paranoid } \\
\text { Score }\end{array}$} & Equal variances assumed & 27.878 & .000 & -4.423 & 118 & .000 & -.367 & .083 & -.531 & -.202 \\
\hline & Equal variances not assumed & & & -4.423 & 112.972 & .000 & -.367 & .083 & -.531 & -.202 \\
\hline \multirow{2}{*}{ Schizophrenia_score } & Equal variances assumed & .701 & .404 & -6.276 & 118 & .000 & -.500 & .080 & -.658 & -.342 \\
\hline & Equal variances not assumed & & & -6.276 & 117.767 & .000 & -.500 & .080 & -.658 & -.342 \\
\hline \multirow{2}{*}{ Depression_score } & Equal variances assumed & .624 & .431 & -.395 & 118 & .693 & -.033 & .084 & -.200 & .134 \\
\hline & Equal variances not assumed & & & -.395 & 117.881 & .693 & -.033 & .084 & -.200 & .134 \\
\hline \multirow{2}{*}{$\begin{array}{l}\text { Hypochondriasis_ } \\
\text { score }\end{array}$} & Equal variances assumed & 140.033 & .000 & -4.365 & 118 & .000 & -.283 & .065 & -.412 & -.155 \\
\hline & Equal variances not assumed & & & -4.365 & 76.190 & .000 & -.283 & .065 & -.413 & -.154 \\
\hline \multirow{2}{*}{ Psychasthenia Score } & Equal variances assumed & 36.974 & .000 & -2.701 & 118 & .008 & -.150 & .056 & -.260 & -.040 \\
\hline & Equal variances not assumed & & & -2.701 & 83.271 & .008 & -.150 & .056 & -.260 & -.040 \\
\hline
\end{tabular}

for the manifestation/development of drug dependent problems among drug addicts than non-drug addict psychiatric patients. This finding support the third hypothesis which predicted relationship effect between individual with antisocial personality disorder and psychopathology among drug addicts and nondependent psychiatric patients.

\section{Summary}

1) Drug addicts manifested antisocial personality disorder than nondependent psychiatric patients.

2) Drug addicts manifested more psychopathology than nondependent psychiatric patients.
3) The prevalence of antisocial personality disorder and other psychopathologies were found high among drug addicts than nondependent psychiatric patients.

\section{Discussion}

The result presented in table 4 support the hypothesis of this study. The first hypothesis that there will be a significant difference between participants with antisocial personality disorder and those without antisocial personality disorder in the development of substance dependent problems support the research. This shows that participants with antisocial personality disorder differed significantly with 
Table 6. A Summary table of Pearson correlation analysis with equal sample size indicating relationship effect between antisocial personality disorder participants and psychopathology participants

\begin{tabular}{|c|c|c|c|c|c|c|c|c|}
\hline & & $\begin{array}{l}\text { ASPD } \\
\text { score }\end{array}$ & $\begin{array}{l}\text { Paranoid } \\
\text { score }\end{array}$ & Depression_score & $\begin{array}{l}\text { Hypochondriasis } \\
\text { score }\end{array}$ & $\begin{array}{c}\text { Psychasthenia_ } \\
\text { score }\end{array}$ & \begin{tabular}{|c|}
$\begin{array}{l}\text { Schizophrenia_ } \\
\text { score }\end{array}$ \\
\end{tabular} & Mania_score \\
\hline \multirow{3}{*}{ ASPD Score } & Pearson Correlation & 1 & $.280^{* * *}$ & .158 & .168 & .154 & $.198^{*}$ & .147 \\
\hline & Sig. (2-tailed) & & .002 & .084 & .066 & .093 & .030 & .109 \\
\hline & $\mathrm{N}$ & 120 & 120 & 120 & 120 & 120 & 120 & 120 \\
\hline \multirow{3}{*}{ Paranoid Score } & Pearson Correlation & $.280^{* *}$ & 1 & -.067 & .133 & $.277^{* *}$ & $.282^{* *}$ & $.372^{* *}$ \\
\hline & Sig. (2-tailed) & .002 & & .465 & .147 & .002 & .002 & .000 \\
\hline & $\mathrm{N}$ & 120 & 120 & 120 & 120 & 120 & 120 & 120 \\
\hline \multirow{3}{*}{ Depression Score } & Pearson Correlation & .158 & -.067 & 1 & .177 & .064 & .087 & -.088 \\
\hline & Sig. (2-tailed) & .084 & .465 & & .053 & .485 & .343 & .338 \\
\hline & $\mathrm{N}$ & 120 & 120 & 120 & 120 & 120 & 120 & 120 \\
\hline \multirow{3}{*}{ Hypochondriasis Score } & Pearson Correlation & .168 & .133 & .177 & 1 & .122 & $.314^{* *}$ & .084 \\
\hline & Sig. (2-tailed) & .066 & .147 & .053 & & .185 & .000 & .359 \\
\hline & $\mathrm{N}$ & 120 & 120 & 120 & 120 & 120 & 120 & 120 \\
\hline \multirow{3}{*}{ Psychasthenia Score } & Pearson Correlation & .154 & $.277^{* *}$ & .064 & .122 & 1 & $.283^{* * *}$ & .145 \\
\hline & Sig. (2-tailed) & .093 & .002 & .485 & .185 & & .002 & .115 \\
\hline & $\mathrm{N}$ & 120 & 120 & 120 & 120 & 120 & 120 & 120 \\
\hline \multirow{3}{*}{ Schizophrenia Score } & Pearson Correlation & $.198^{*}$ & $.282^{* *}$ & .087 & $.314^{* *}$ & $.283^{* *}$ & 1 & $.415^{* *}$ \\
\hline & Sig. (2-tailed) & .030 & .002 & .343 & .000 & .002 & & .000 \\
\hline & $\mathrm{N}$ & 120 & 120 & 120 & 120 & 120 & 120 & 120 \\
\hline \multirow{3}{*}{ Mania Score } & Pearson Correlation & .147 & $.372^{* *}$ & -.088 & .084 & .145 & $.415^{* *}$ & 1 \\
\hline & Sig. (2-tailed) & .109 & .000 & .338 & .359 & .115 & .000 & \\
\hline & $\mathrm{N}$ & 120 & 120 & 120 & 120 & 120 & 120 & 120 \\
\hline
\end{tabular}

participants without antisocial personality disorder in the development of substance dependent problems. That is to say that, drug addicts differed significantly with nondependent psychiatric patients in the development of substance dependent problems. The data and the result indicate that participants with antisocial personality disorder had higher score than participants without antisocial personality disorder. This may be a result of the following according DSM-V:

"A. A pervasive pattern of disregard for and violation of the right of others, occurring since the age of 15 years, as indicated by three (or more) of the Following:

1. Failure to conform to social norms with respect to lawful behaviors, as indicated by repeatedly performing acts that are grounds for arrest

2. Deceitfulness, as indicated by repeated lying, use of aliases, or conning others for personal profit or pleasure

3. Impulsivity or failure to plan ahead

4. Irritability and aggressiveness, as indicated by repeated physical fight or assaults

5. Reckless disregard for safety of self or others

6. Consistent irresponsibility, as indicated by repeated failure to sustain consistent work behavior or honor financial obligations

7. Lack of remorse, as indicated by being indifferent to or rationalizing having hurt, mistreated/or stolen from another

B. The individual is at least age 15 years

C. There is evidence of conduct disorder with onset before 15 years

D. The occurrence of antisocial behavior is not excessively during the worse of Schizophrenia or bipolar disorder".

This result confirmed and is in line with $[9,10,13]$ 's studies. According to them, antisocial personality disorder described as irresponsible behavior and lack of remorse for misdeeds which develop during childhood or early adolescent and persist into adulthood contributes to the risk of developing drug addiction or substance dependent problems.

The result of the study also confirms the second hypothesis which predicted that a statistical significance difference will exit between participants with psychopathology and those without psychopathology in the development of substance dependent problems (Table 5). That is to say that, presence of psychopathology namely mania, paranoid, schizophrenia, psychasthenia and hypochondriasis among drug addicts differed significantly with non-drug addict psychiatric patients. This finding is in line with, studies $[3,8]$. Also, Rounsavilla et al. study confirmed it and is in line with the study [8].

They all indicated that there is high prevalence rate of substance dependence with psychopathology. This indicated that psychopathology play a role in precipitating substance dependence problems among drug addicts than nondrug dependence psychiatric patients. That is to say that, drug addicts are likely to develop psychopathology than nondrug dependence psychiatric patients.

From the above, the results generally meet the prediction of this study. The results have provided the basis for answering some of the questions raised in the study. The significant difference found in the study between participants of antisocial personality disorder and participants of non-antisocial personality disorder (that is, between drug addicts and nondrug dependence psychiatric patients) and participants with psychopathology and those without psychopathology (that is, between drug addicts and nondrug dependence psychiatric patients), is quite revealing.

The spearman correlation summary table (Table 6) also indicate a significant relationship between antisocial personality disorder and psychopathology at $\mathrm{p}<.01$. When this variables are considered jointly that is, ASPD with schizophrenia, ASPD with mania, ASPD with paranoid schizophrenia, ASPD with psychasthenia and ASPD 
with hypochondriasis, support for their combine effect in moderating substance dependence among drug addicts was found. This indicate that antisocial personality disorder and psychopathology combine to moderate substance dependence problems among drug addicts.

In summary, this suggests that the prevalence of antisocial personality disorder and psychopathology in moderating substance dependence problems among drug addicts is strong when antisocial personality disorder and psychopathology are considered independently or separately and also when they are considered in combination or relationship.

This finding provide support for the hypothesis that antisocial personality disorder and psychopathology namely (schizophrenia, mania, paranoid schizophrenia and hypochondriasis) among drug addicts are contributing factors to the development/manifestation of substance dependence problems among drug addicts. The findings of other researchers mentioned above confirmed this assertion.

\section{Conclusion}

The result obtained from this study show that there exists significant difference between antisocial personality disorder (drug addicts and nondependent psychiatric patients) and psychopathology (drug addicts and nondependent psychiatric patients) among drug addicts. It demonstrates that antisocial personality disorder and psychopathology are related to or associated with substance dependent problems. Thus, researcher concludes that variables that predispose individuals to substance dependence problems are psychological. In this study, antisocial personality disorder and psychopathology were implicated in substance dependence. This is in line with other researchers/authorities sited in the study above. The researcher thinks that this is a challenge to which Clinical Psychologists must rise to considering the overwhelming influence of psychological variables on health.

\section{Acknowledgement}

The authors acknowledge the support, approval and permission of Health Research Ethical Committee of Federal Neuropsychiatric Hospital (FNHP), Barnawa, Kaduna to conduct the study in the DATER unit and in the male and female wards of the hospital, including Clinical Psychologists who assisted in the interview and the administration of the MMPI-2 questionnaire. Also, our sincere thanks to all the patients who shared their views in attending to the questionnaire and interview in the study.

\section{Declaration of conflicting interests}

Authors declare they have no conflicting interests.

\section{References}

1. Dorus W, Senay EC (1980) Depression, demographic dimensions, and drug abuse. Am J Psychiatry 137: 699-704. [Crossref]

2. Eleftherim CA, Coannis FN, Thomas WW (2010) Prevalence Rate of Substance Dependence with Psychopathology. Arch Gen Psychiatry 158: 307-314.

3. Ross HE, Glaser FB, Germanson T (1988) The prevalence of psychiatric disorders in patients with alcohol and other drug problems. Arch Gen Psychiatry 45: 1023-1031. [Crossref]

4. Rounsaville BJ, Weissman MM, Kleber H, Wilber C (1982) Heterogeneity of Psychiatric Diagnosis in Related Opiate Addicts. Arch Gen Psychiatry 39: 161-166. [Crossref]

5. Khantzian EJ, Treece C (1985) DSM-III psychiatric diagnosis of narcotic addicts Recent findings. Arch Gen Psychiatry 42: 1067-1071. [Crossref]

6. International Classification of Diseases (ICD-10) (2015) Encyclopedia Britannica Ultimate Reference Suite. Chicago: Encyclopedia Britannica.

7. International Statistical Classification of Diseases and Related Health Problems (1993). Tenth Revision, Geneva World.

8. Rounsavilla DJ, Anton SF, Carrol K, Budde D, Prusoff BA, et al. (1991) Psychiatric Diagnosis of Treatment-Seeking Cocaine Abuse. Arch Gen Psychiatry 48: 43-51. [Crossref]

9. Baoliang Z, Yan L, Junhoy Z, Helen FK (2014) Antisocial Personality Disorder among Chinese

10. Individuals Receiving Treatment for Heroine Dependence: a Meta-analysis Shanghai Arch Gen Psychiatry 26: 259-271.

11. Darke S, Williamson A, Ross J, Teeson M, Lynskey M (2004) Borderline Personality Disorder, Antisocial Personality Disorder and Risk Taking among Heroin Users: Finding from the Australian Treatment outcome Study (ATOS). Drug Alcohol Depend 74: 77-83. [Crossref]

12. Grant BF, Stinson FS, Dawson DD, Chou PS, Ruan JW, et al. (2006) Co-occurrence 12 Months Alcohol and Drug User Disorder and Personality Disorders in United States Result from the National epidemiological Survey on Alcohol and Related Condition. Arch Gen Psychiatry 29: 121-131.

13. Rounsaville B, Kleber HO (1986) Psychiatric Disorder in Opiate Addicts, in R-E Myers. Psychopathology Addictive Disorder. New York: Oxford University Press. 140168

14. Glenn A, Johnson A, Raine A (2013) Antisocial personality Disorder: A Current Review. Curr Psychiatry Rep 15: 427. [Crossref]

Copyright: (2018 Oguizu OJ. This is an open-access article distributed under the terms of the Creative Commons Attribution License, which permits unrestricted use, distribution, and reproduction in any medium, provided the original author and source are credited. 